Case Study

http://dx.doi.org/10.20546/ijcmas.2016.504.035

\title{
Scrub Typhus (Chigger - Borne Typhus): A Case of Scrub Typhus with Eschar
}

\author{
D.Therese Mary* \\ Institute of Microbiology Madras Medical College Chennai Tamil Nadu India \\ *Corresponding author
}

\section{A B S T R A C T}

Keywords

Scrub Typhus,

Eschar,

Chiggers.

\section{Article Info}

Accepted:

15March 2016

Available Online:

10 April 2016
Scrub Typhus is a place disease caused by Orientia tsutsugamushi an obligate intracellular gram negative bacteria. It is found in areas with a suitable climate, plenty of moisture and scrub vegetation. The vectors are trombiculid mites. Human beings are infected when they are bitten by the mite larvae (chiggers). We report a case of $2 \frac{1}{2}$ yrs old male child who presented with fever, headache and eschar on the Right Thigh. The child was investigated for scrub typhus as he had classical features. Child was positive for scrub typhus and he recovered with proper antibiotic therapy.

\section{Introduction}

Scrub typhus originally found in scrub jungles has also been identified in other habitats such us sandy beaches, mountain deserts and equatorial rain forests. It is endemic in certain parts of the world. It occurs along East Asia and in the Pacific island including Australia. The organism Orientia tsutsugamushi causative agent of scrub typhus was formerly classified as ricketssia. As it has a different cell wall structure and genetic composition from ricketssiae it is classified as a gram negative bacteria. (Tamura et al., 1995) The incubation period is 1-3 weeks. The disease can present with fever, headache, rash, lymphadenopathy and conjunctival injection. Encephalitis and pneumonia may be seen in severe cases.
We report a case of scrub typhus in a $2^{1 / 2 y r s}$ old male child for the classical presentation with eschar, fever and headache.

\section{Case Report}

A $2 \frac{1}{2}$ yrs old male child from South Chennai was brought with eschar on the Right thigh associated with fever, headache, regional lymphadenopathy and conjunctival injection for 3 days. History revealed thick vegetations near the residence and child used to play around the area.

Complete blood count was done. TLC $3800 / \mathrm{mm}^{3}$ with polymorphs $70 \%$, Lymphocytes 23\%, eosinophils $4 \%$ and monocytes $3 \%$. His hemoglobin was 10.5 
gm \%, platelet count was 1.7lakhs and ESR was $19 \mathrm{~mm}$ at 1 hour. Blood sample was collected for Elisa test and Weil-Felix test. IgM Elisa was done at the end of 1 week using IN BIOS ELISA kit and it was reactive. Weil-Felix test was positive in $1 / 160$ dilution. Child was started on azithromycin $5 \mathrm{mg} / \mathrm{kg}$ as a single dose orally. Within 3 days of initiation of antibiotic therapy symptomatic improvement was observed. Antibiotic was given for a course of 5 days.

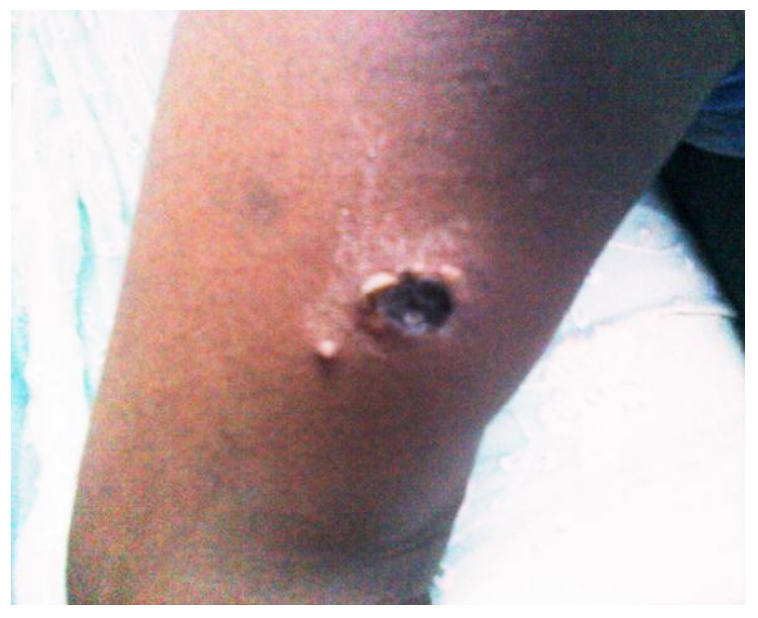

\section{Discussion}

Scrub typhus a dreaded disease in pre antibiotic era is a militarily important disease that caused thousands of cases during the second world war. (Beran, 1994) It is endemic to a part of the world known as the tsutsugamushi triangle which extends from Northern Japan and far-Eastern Russia in the North, to Northern Australian in the South and to Pakistan in the West. (McCrub et al., 1957) In India it is prevalent in many parts. Out breaks have been reported in Himachal Pradesh, Sikkim, Darjeeling and Southern India during the cooler months of the year. Scrub typhus is a reemerging infectious disease in India. (Padbidri and Gupta, 1978)

Orientia tsutsugamushi is an obligate intracellular gram negative bacterium which grows freely in the cytoplasm of infected cells. The five major serotype are Boryon, Gilliam, Karp, Kato and Kawazaki. Humans acquire the disease from the bite of an infected chigger. The mite bite leaves a black eschar which is useful for clinical diagnosis. (Lerdthusnee et al., 2002; Lerdthusnee et al., 2003) The non-specific presentation and lack of the characteristic eschar in $40 \%$ patients makes the misdiagnosis and under reporting of scrub typhus common. (Silpapojakul, 1997) Clinical features of scrub typhus are fever with chills, headache, conjunctival injection, lymphadenopathy and spotted rash on the trunk.

This $2 \frac{1}{2}$ yrs old male child had the classical eschar on Right thigh associated with very high fever $\left(>103^{\circ}\right)$, headache and lymphadenopathy. History revealed thick vegetations around the house.

History and the characteristic eschar gave clue in suspecting scrub typhus. The diagnostic tests available are the Weil Felix test, IgM Elisa, Molecular detection using polymerase chain reaction (PCR) and Indirect Immunoflourescence antibody test;which is the;gold standard test. WeilFelix test is unreliable and Elisa provides more sensitivity and good specificity. (Brown et al.,1981)

For this child Weil-Felix test was positive and the IgM scrub typhus Elisa test was reactive.

The antibiotics of choice for scrub typhus are doxycycline, chloromphenicol and azithromycin; As the patient was a child, he was put on azithromycin $5 \mathrm{mgm} / \mathrm{kg}$ body weight for 5 days. Antibiotic therapy brought dramatic clinical improvement. Rapid defervescence after antibiotic 
treatment is so characteristic that it is used as a diagnostic test for Orientia tsutsugamushi infection. (Chouriyagune et al., 1996) Scrub Typhus mimics other forms of typhus fever, typhoid fever, leptospirosis, dengue fever etc. during the first few days. The geographical location of scrub typhus, eschar by chigger bite and the antibody test are useful in establishing diagnosis.

Prophylaxis in the form of protective clothings, application of insect repellants can prevent chigger bites. Clearing of vegetation and chemical treatment of the soil may help to break up the cycle of transmission from chiggers to humans.

\section{References}

Tamura, A., Ohashi, N., Urakami, H., Miyamura, S. 1995. Classification of Rickettsia tsutsugamushi in a new genus, Orientia gen nov, as Orientia tsutsugamushi comb, nov. Int. J. Syst. Bacteriol., 45: 585-591.

Beran, G.W. 1994. Scrub typhus in: Handbook of Zoonoses. Second Edition. Section A: Bacterial, Rickettsial, Chlamydial and Mycotic. CRC Press, 663-668.

McCrub, F.R., Stockard, J.L., Robinson, C.R., Turner, L.H., Levis, D.G., Maisey, C.W., Kelleher, M.F., Gleiser, C.A., Smadel, J.E. 1957. American J. Trop. Med. Hyg., 6: 238256.
Padbidri, V.S., Gupta, N.P. 1978. Rickettsiosis in India: A review. $J$. Indian Med. Assoc., 71: 104-107.

Lerdthusnee, K., Khlaimanee, N., Monkanna, T., Sangjun, N., Mungviriya, S., Linthicum, K.J., Frances, S.P., Kollars, T.M., Jr. Coleman, R.E. 2002. Efficiency of Leptotrombidium Chiggers at Transmitting Orientia tsutsugamushi to Laboratory Mice. J. Med. Entomol., 39(3): 521-525.

Lerdthusnee, K., Khuntirat, B., Leepitakrat, W., Tanskul, P., Monkanna, T., Khlaimanee, N., Inlao, I., Kengluecha, A., Mungviriya, S., Chandranoi, K., Krairojananan, P., Bodhidatta, D., Rodkwamthook, W., Phulsuksombati, D., Sangjun, N., Watcharapichat, P., Jones, J.W., Coleman, R.E. 2003. Scrub Typhus: Vector competence of leptotrombidium chiangraiensis chiggers and transmission efficacy \& isolation of Orientia tsutsugamushi. Ann. N.Y. Acad. Sci., 990: 25-35.

Silpapojakul, K. 1997. Scrub typhus in the Western Pacific region. Ann. Acad. Med. Singapore, 26: 794-800.

Brown, G.W., Shirai, A., Gan, E., Bernthal, P. 1981. Antibodies to typhus in Eastern Nepal. Trans. Roy. Soc. Trop. Med. Hyg., 75: 586-587.

Chouriyagune, G., Ruangweerayud, C., Watcharapichat, R., et al. 1996. Scrub typhus infections poorly responsive to antibiotics in northern Thailand, The Lancet, 348(9020): 86-89.

\section{How to cite this article:}

Therese Mary, D., 2016. Scrub Typhus (Chigger - Borne Typhus): A Case of Scrub Typhus with Eschar. Int.J.Curr.Microbiol.App.Sci. 5(4): 303-305. doi: http://dx.doi.org/10.20546/ijcmas.2016.504.035 